\title{
Outcomes of Operatively Treated Acute Knee Dislocations
}

\author{
Vivek Eranki*, Collie Begg and Brian Wallace
}

\author{
The Royal Adelaide Hospital, North Terrace, Adelaide, SA, 5000, Australia
}

\begin{abstract}
Knee dislocation is a complex and rare injury often presenting in the context of high velocity trauma. The aim of this study is to establish the subjective outcomes of surgically treated knee dislocations. A total of 20 knees dislocations treated by open repair were reviewed. Their progress and outcomes were assessed by using a modified Lysholm score questionnaire. Data was obtained on patient demographics, details of injury, investigation, treatment, rehabilitation, 24 months objective outcome and subjective outcomes. Six patients had a vascular deficit and six had neurological deficits. The median range of motion was $0^{\circ}-100^{\circ}$. Patients with an initially lower pre-injury level of function were able to return an activity level comparable to their pre-injury status. $22 \%$ of competitive athletes retuned to competitive sports. $38 \%$ of patients undertaking heavy activity returned to comparable pre-injury level of activity and $67 \%$ of patients undertaking moderate level of activity before injury returned to a comparable level after repair. $68 \%$ regularly had problems running, $70 \%$ problem squatting, $40 \%$ swelling and $42 \%$ problem with stairs. Most patients however did not have locking of the knee or problems with knees giving way. Patients pain scores decreased over time to an acceptable level. Despite the severity of the injury, majority of patients achieved a satisfactory outcome, although none of the patients reached the same level of function as before the injury. $80 \%$ of the patients were satisfied with their outcome. All dissatisfied patients suffered postoperative complications.
\end{abstract}

Keywords: Knee dislocations, traumatic knee dislocations, surgical repair of knee dislocations, outcomes of knee dislocations, knee instability and patient satisfaction post knee repair.

\section{INTRODUCTION}

Dislocation of the knee is due to damage to the soft tissue structures around the knee that provide stability. It is a relatively uncommon but potentially devastating injury. A large proportion of knee dislocations reduce spontaneously [1]. Immediate diagnosis is vital as knee dislocation is associated with a relatively high incidence of neurovascular compromise. Even in cases where the knee neurovasculature is intact, misdiagnosis and incorrect treatment can result in significant long-term loss of range of motion, chronic instability and poor function which affect the patient's activities of daily living. Most knee dislocations occur in the context of high-velocity trauma, when the patient often has other injuries that may take precedence in treatment. In addition, articular cartilage and meniscal injuries and associated fractures can complicate the evaluation and management of knee dislocations [2].

For the purpose of the study, knee dislocation was defined as 'instability of the knee due to complete loss of tibio-femoral articulation, caused by damage to anterior cruciate ligament (ACL) and/or posterior cruciate ligament (PCL) and at least one of medial collateral ligament (MCL), lateral collateral ligament (LCL) and posterolateral complex (PLC).

Several studies so far have described the injury and provided insight into prevalence, pattern of injuries, management options, complications and objective outcomes.

\footnotetext{
*Address correspondence to this author at the Queen Elizabeth Hospital, 28 Woodville Road, Woodville West, SA 5011, Australia; Tel: +61 415179 050; Fax: +61 88121 9294; E-mail: vivek.eranki@me.com
}

Objective assessment is consistent across most literature using range of motion, level of pain, swelling, return to work and sport to describe outcomes. An evidence gap exists on the subjective outcome of operative repair of knee dislocations. Some studies have presented the results of Lysholm score and IKDC. These scoring systems give us a quantitative measure of the patient's assessment of their knee. Good correlation was found between the scoring systems and objective measures, however they cannot track the patient's pain level and activity through time or establish their overall satisfaction with the outcome. This study examines outcomes in existing literature and reviews patients who underwent open repair for acute knee dislocation at the Royal Adelaide Hospital over a 10-year period (1995-2005). The subjective outcomes of these patients were assessed using a modified Lysholm score (Appendix 1). The aim of this study is to establish the subjective outcomes of knee dislocations treated with open repair.

Vascular compromise associated with knee dislocations is a source of significant morbidity. The popliteal artery, because of its attachments both proximal and distal to the knee, is injured in approximately $20 \%$ to $40 \%$ of all knee dislocations $[3,4]$. The incidence can be as high as $50 \%$ [5] in anterior and posterior dislocations [6] and higher with coexisting fractures [7]. Vascular status can be established clinically or through an angiography. Duplex Doppler Ultrasound has been found to be equally as accurate in the elective setting. The accuracy however decreases with skeletal deformity, swelling, haematoma, dressings, and the lack of necessary skill and expertise [7]. Normal vascular examination and observation has been found to be sensitive enough to exclude vascular compromise [8]. Formal 
angiography usually results in a delay of one to two hours, and should be reserved for patients with uncertain distal perfusion. Recently published data reveals increasing support for selective angiography [8, 9].

Neurological deficit was detected on secondary survey in the emergency department. Peroneal nerve injury has been shown to occur in up to $20-30 \%$ of knee dislocations [9-11] and it is more common in ACL, MCL and PLC disruption [11]. Spontaneous recovery in neurological symptoms can occur in up to $20 \%$ of cases [12]. Nerve grafting or transfer of tibialis posterior can be considered as a reconstructive procedure. Transfer of the tibialis posterior tendon is effective in restoring some dorsiflexion.

Treatment can be summarised into two broad categories of operative and non-operative. Historically, non-operative management was favoured [13] however recent literature has advocated early surgical repair [14]. No set protocol exists for the timing of repair and the pattern of ligament repair. Most authors however advocate early repair of the posterolateral complex usually within 10-14 days of injury [9]. With cruciate repair, there is a debate as to which cruciate ligament must be first reconstructed. Early isolated repair of PCL has shown better results than isolated repair of ACL [9, 14]. Reconstruction of both cruciates leads to a higher incidence of fibrosis and poorer functional result but improved stability [15].

\section{MATERIALS AND METHODOLOGY}

A hospital ICD-10 database search was performed using the terms 'dislocation' or 'subluxation' of the 'knee', 'proximal tibia' or 'joint of the lower leg'. This search yielded 127 patients with 128 knee dislocations. Most of these patients were excluded from the study. Exclusions were based on misdiagnosis/unclear diagnosis, instability caused by fracture without ligament disruption, ligamentus injury not consistent with the study's definition of knee dislocation, cases treated non operatively, patients who did not undergo open repair (as described in methodology) and patients with incomplete information in case notes and failed to complete or return questionnaires. This left 20 cases of knee dislocations suitable for the study.

These case notes were reviewed to obtain information on patient age at the time of injury, residence, other injuries, treating consultant, date of injury, mechanism of injury, ligaments damaged, diagnostic investigations performed, treatment, and range of motion at 24 months. The method of injury was classified as either high-velocity or low-velocity injuries. High-velocity injury included motor vehicle accidents and motor-cycle accidents. Low-velocity accidents were due to falls and sporting accidents. Patients who partake in competitive sports were categorised as competitive athletes. Patients who partake in recreational sports at least 5 times per week and/or heavy labor were categorised into heavy activity. Patients who work in moderately heavy labor, light labor and walk on uneven ground at least twice a week were categorised into moderate activity and patients who lead a sedentary lifestyle were categorised into minimal activity.

At the Royal Adelaide Hospital, the timing of the surgery was based on the type of trauma. Patients with vascular compromise were operated on with urgency to reduce morbidity. In vascularly intact patients, operative repairs of knees were done within 14 days of injury since longer wait could result in scarring and contractures, which can cause increased stiffness and decreased range of motion. A lateral or a medial incision was used to maximise access to damaged structures. Tourniquet was used unless contraindicated. Avulsions were re-attached using sutures through trans-osseous tunnels or using staples. Cruciate reconstructions were done using a bone-tendon-bone autograft. The autografts were usually harvested from the patella or hamstring. Collateral ligamentus ruptures were repaired using non soluble sutures. Posterolateral capsule ruptures were repaired by first exposing the capsule. The repair focused on anatomic restoration of the disrupted structures using sutures. All patients underwent rehabilitation post operatively.

Post operatively, all patients were immobilised in a cast brace with a hinge for 6 weeks and underwent rehabilitation. The first month of rehabilitation consisted of achieving the maximum possible range of motion; this was followed by strengthening exercises. After three months, the patients' commenced light activity while avoiding sudden change of direction. Normal levels of activity could be undertaken after 12 months. During this time, the patients were regularly followed through the outpatient clinics. At the 24 months OPD, ROM was assessed along with complications. Range of motion was examined using a manual goniometer. 'Satisfactory' functional outcome is defined as range of motion between $10^{\circ}$ fixed flexion deformity and $90^{\circ}$, 'good' outcome is defined as range of motion between $0^{\circ}$ and $130^{\circ}$ and 'normal' $\mathrm{ROM}$ is flexion between $130^{\circ}$ and $150^{\circ}$ (Table 1).

Table 1. Outcomes Based on Range of Motion

\begin{tabular}{|c|c|c|}
\hline Outcome & Range of Motion & \% of Patients \\
\hline \hline Satisfactory & $\begin{array}{c}\text { Fixed flexion deformity }>10^{\circ} \\
\text { Flexion }<90^{\circ}\end{array}$ & $23 \%$ \\
\hline Good & $0^{\circ}$ and $130^{\circ}$ & $54 \%$ \\
\hline Normal & $\begin{array}{c}\text { No Fixed flexion deformity } \\
\text { Flexion }>130^{\circ}\end{array}$ & $15 \%$ \\
\hline
\end{tabular}

Patients satisfying the inclusion criteria for the study were contacted by phone and/or mail and asked to complete a modified Lysholm rating system questionnaire [16]. Questions were on knees giving way, problems with stairs, running, locking, swelling, problems squatting and support when walking, limp, satisfaction with the procedure, pain, complications and further medical management after discharge (Appendix 1).

\section{RESULTS}

The study included 20 knee dislocations. Their ages ranged from 17 to 79 with the mean age 34, median 33 and standard deviation of 17. Left to right was 13:7. More males had knee dislocations than females (14:6). Fifteen knees (75\%) were dislocated following a high-velocity injury and five following a low-velocity injury. All 20 patients were treated operatively and followed up in the Royal Adelaide 
Hospital Outpatients. They were later approached with a modified Lysholm questionnaire for subjective evaluation.

All patients had a vascular examination by a member of the vascular team. All cases of popliteal artery damage were diagnosed clinically and confirmed by angiogram. Eleven patients had an angiogram because of suspicious or inconclusive findings on vascular examination, nine had a magnetic resonance imaging (MRI) scan and five had both an MRI and an angiogram. Six patients were found to have a vascular deficit. $75 \%$ of the vascular injuries occurred in patients with associated lower limb fractures. Sixteen of the 20 patients had co-existing injuries; eight of these had fractures.

Neurological assessment of the lower limb was carried out on patients in the emergency department once the primary survey was complete. This secondary survey detected six patients with a neurological deficit. The most frequently damaged nerve was the common peroneal nerve. $83 \%$ of the patients with neurological deficit had disruption of the posterolateral complex.

ACL/PCL/MCL was the most common injury. This was followed by injury to PCL/LCL/PLC and then to all five ligaments. There were many unique combinations of ligament damage totalling 8 . There were 12 anterior dislocations (disrupted ACL) and 17 posterior dislocations (disrupted PCL); often anterior and posterior compromise co-existed.

Immediately after surgery, all patients complained of pain and stiffness. Other complications included superficial wound infection (3 patients), pulmonary embolism (1 patient) and compartment syndrome (1 patient).
Objective assessment was carried out in the clinics. At the 12 month outpatient department visit, the median extension was $0^{\circ}$ with a range of $-10^{\circ}$ to $15^{\circ}$, and the median flexion was $100^{\circ}$ with a range of $70^{\circ}$ to $140^{\circ}$. Fixed flexion deformity was noted in 2 patients. Outcomes based on ranges of motion is summarised in Table $\mathbf{1}$.

Activity was defined as competitive, heavy, moderate and minimal. Patient activity was graphed in Figs. (1-3) for competitive athletes, heavy activity and moderate activity respectively. None of the patients achieved a higher level of activity than pre-injury; 7 patients achieved the same level of activity; 10 were worse by one category, and 3 were worse by more than one category. Greater proportion of patients with a low pre-injury level of activity returned to a level comparable to their pre-injury level compared to patients with a higher pre injury level of activity. All patients with a moderate level of pre-injury activity had either returned to their original level or worsened by only one category. However, of the 9 competitive athletes, only 2 achieved the same level of activity after recovery from the injury; 4 were worse by one category, and 3 had significant loss in their post-injury activity (i.e. worse by more than one category). Nevertheless, most patients, regardless of their pre-injury level of activity, finished with a moderate level of activity in that they were able to comfortably walk on uneven surfaces, and undertake light and moderately heavy labour.

Fig. (4) demonstrates the median level of pain in patients immediately after injury, 3 months after the injury and at the time of the questionnaire. Severe pain is defined as greater than 7 and low/acceptable pain level lower than 3 . Immediate after surgery, all patients reported pain in the knee. The mean pain score was 6 with a median of 7 . The

\section{Competitive Athelete}

Currently

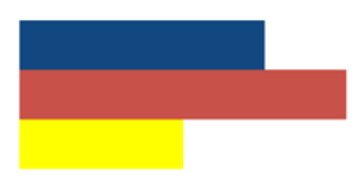

After 3 months

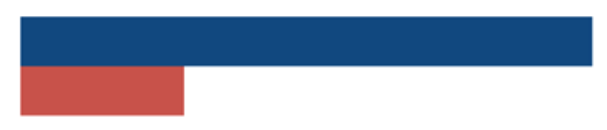

>1 category

Worse by 1

category

Same

Fig. (1). Level of activity following treatment of knee dislocation in competitive athletes immediately after treatment, 3 months after treatment and currently. 


\section{Heavy Activity}

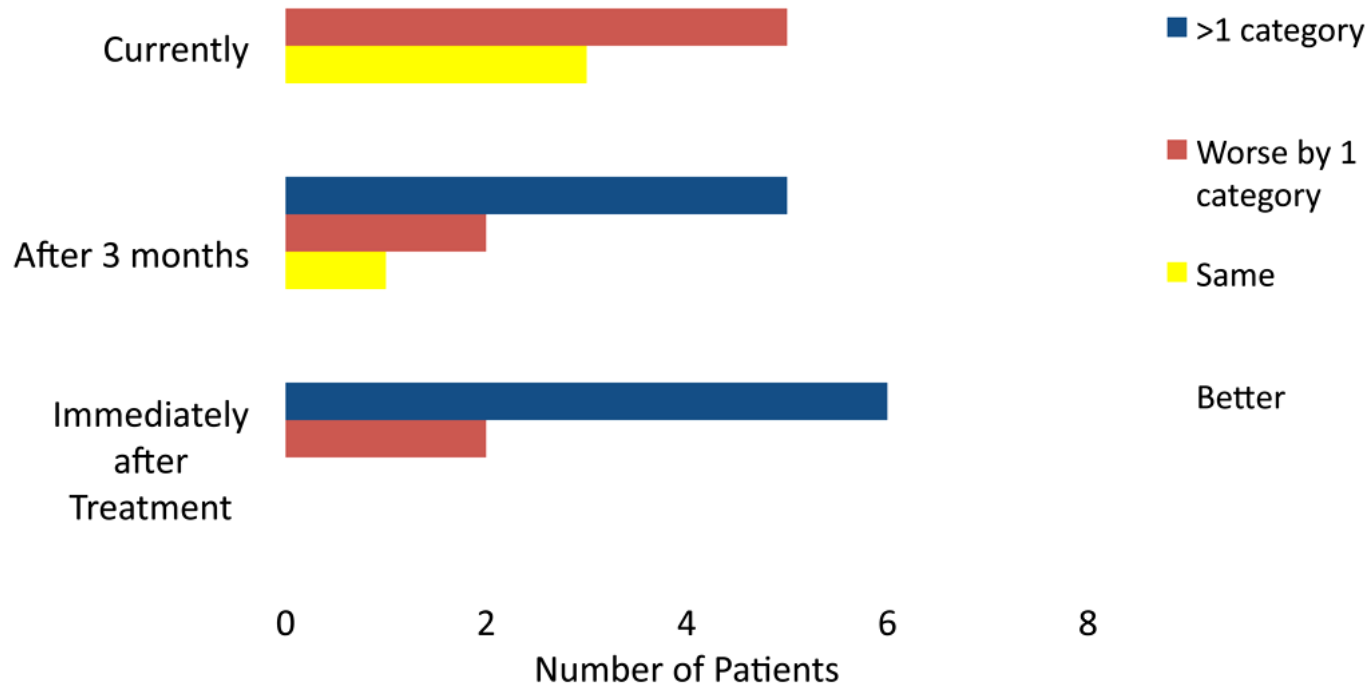

Fig. (2). Level of activity following treatment of knee dislocation in patients undertaking heavy activity, immediately after treatment, 3 months after treatment and currently.

\section{Moderate Activity}

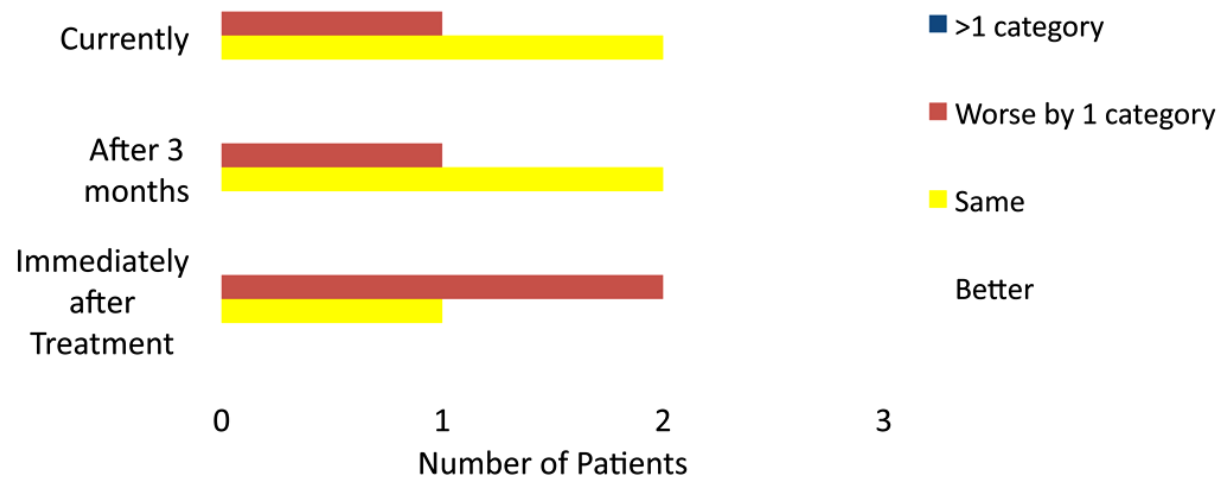

Fig. (3). Level of activity following treatment of knee dislocation in patients undertaking moderate activity, immediately after treatment, 3 months after treatment and currently.

pain ranged from 2 to 10 with a standard deviation of 2.5 . Three months after surgery, the mean and median pain scores were 4 . The pain ranged from 1 to 7 with a standard deviation of 2 . At the time of the questionnaire, mean pain score was 2 with a median of 1.5 . The pain ranged from 0 (nil) to 7 with a standard deviation of 2 . As expected, all patients had a high level of pain immediately after the injury. The levels declined with time following treatment.

Fig. (5) demonstrates the responses to these questions. Even after treatment and rehabilitation, many patients had difficulty undertaking activities that strained the knee; $68 \%$ regularly had problems running, and $70 \%$ had problem squatting. High numbers of surgically treated patients have regular problems with swelling (40\%) and stairs (42\%). Most patients however did not have locking of the knee or problems with knees giving way. In the patients who are suffering from their knee giving way, most had problems with going down rather than up stairs, did not have locking of the knee, and were able to walk without an aid. Post rehabilitation, twenty-five percent of patients complained of a moderate to severe limp. Thirty percent of patients did not have any limp. Sixty eight percent of patients could perform most activities of daily living. Of those who had been 


\section{Pain Score}

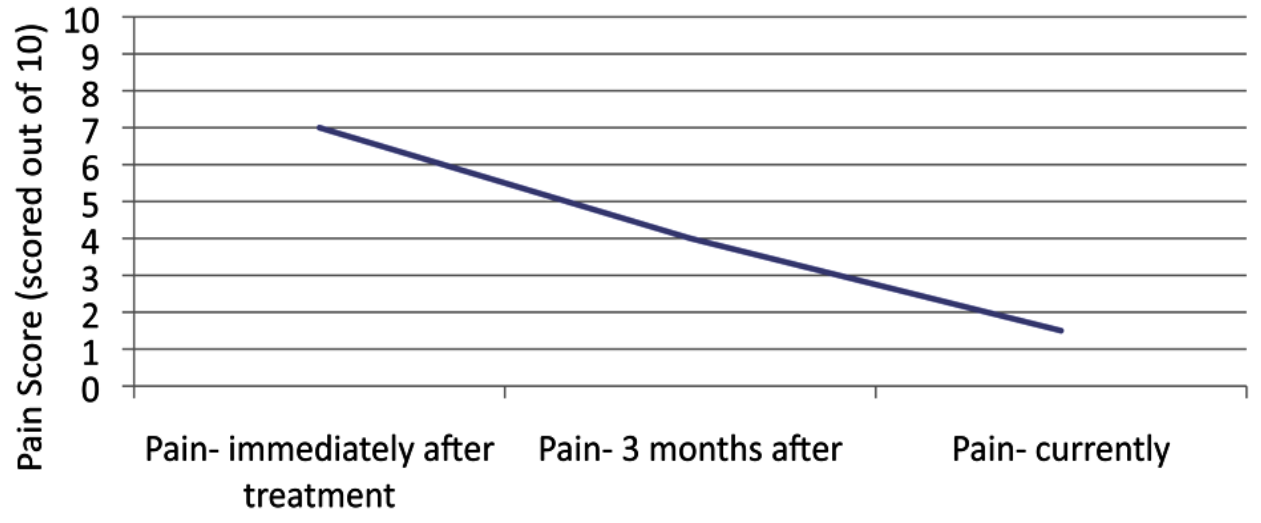

Fig. (4). Patient's level of pain following knee dislocation.

employed, Sixty three percent were able to return to normal work. Most patients, however, found it difficult to return to sport. Only two of the competitive athletes returned to competitive sports.

The patients' levels of satisfaction were also measured in the questionnaire. The level of patient satisfaction is shown in Fig. (6). 80\% of the patients were satisfied with their outcome. The dissatisfied patients suffered postoperative complications, most commonly wound infections.

\section{DISCUSSION}

Knee dislocations are serious in nature and must be dealt with as high priority. It is also an injury with a young median population. All patients underwent open repair and were rehabilitated in an inpatient and outpatient basis. Progress was followed up in clinic and subjective assessment was conducted through a mail out questionnaire/over the phone.

There are several undesirable complications of knee dislocations with joint stiffness and decrease in range of motion being very common. These are caused by haemarthrosis with secondary fibrotic adhesions, scar formation involving normally gliding capsular or ligamentous tissue, muscle contractures, joint contractures, non-isometric reconstruction, arthrofibrosis, infrapatellar contracture syndrome, complex regional pain syndrome, infection, notch scarring, prolonged immobilisation, and scarring of the extensor mechanism [17]. Loss of range of motion has significant impact on patient's activity of daily living. Loss of extension (fixed flexion deformity) has been shown to have a greater affect on the knee's function than

\section{Function}

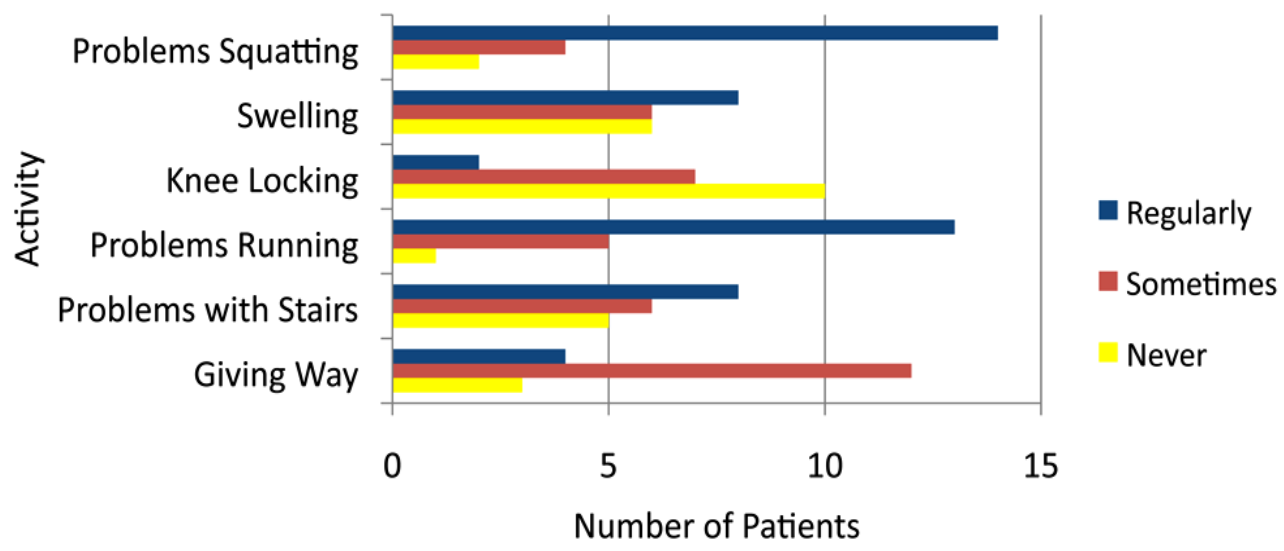

Fig. (5). Patient's level of function following treatment of knee dislocation. 


\title{
Patient Satisfaction
}

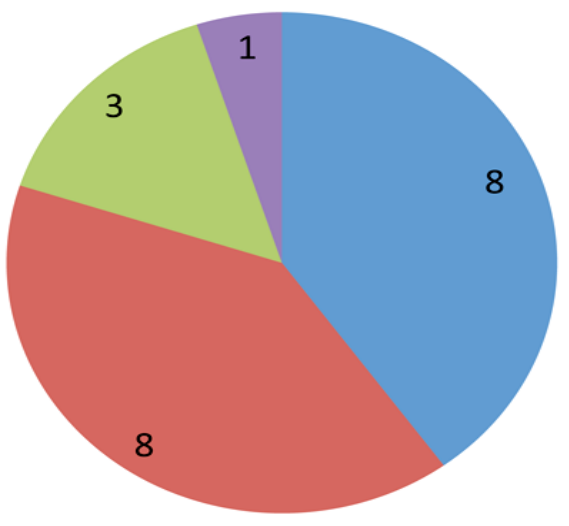

\author{
Very Satisfied
}

- Somewhat satisfied

Somewhat
dissatisfied

Very dissatisfied

Fig. (6). Patient level of satisfaction.

loss of flexion [18]. To minimise this, patients are encouraged to undertake regular rehabilitation through a physiotherapist. After repair, all patients are referred to a physiotherapist for rehabilitation. Physiotherapy and rehabilitation equips the patients with stretching and weight bearing exercise to prevent de-conditioning and aid return of function. Several studies have reported the ranges of motions of patients treated operatively. These results are summarised in Table 2. The average flexion post operatively of the literature reviewed is $124^{\circ}$.

Rehabilitation has a well documented positive effect on the range of motion. Shapiro et al. found the average range of motion gained through rehabilitation was $60^{\circ}$ [19]. Nine months of rehabilitation has been found to be necessary to gain the maximum range of motion and strength post operatively [20]. The median range of motion in this study was $100^{\circ}$. $10 \%(2 / 20)$ patients were found to have a fixed flexion deformity. In this study, objectively, only a few patients regained satisfactory range of motion in their knee; however, subjectively most were happy with the result.

Table 2. Range of Motion

\begin{tabular}{|l|c|c|c|}
\hline \multicolumn{1}{|c|}{ Author } & $\begin{array}{c}\text { Mean } \\
\text { Flexion }\end{array}$ & $\begin{array}{c}\text { Fixed Flexion } \\
\text { Deformity } \\
\text { (\% of Patients) }\end{array}$ & $\begin{array}{c}\text { Lysis of } \\
\text { Adhesions }\end{array}$ \\
\hline \hline Wong et al. $[24]$ & $128^{\circ}$ & - & - \\
\hline Shapiro et al. $[19]$ & $115^{\circ}$ & $43 \%$ & $14 \%$ \\
\hline Klimkiewicz et al. $[21]$ & $128^{\circ}$ & - & - \\
\hline Tzurbakis et al. $[22]$ & $129^{\circ}$ & - & $12 \%$ \\
\hline Yeh et al. [29] & $130^{\circ}$ & $24 \%$ & - \\
\hline Harner et al. [17] & $129^{\circ}$ & $4 \%$ & - \\
\hline Montgomery et al. [34] & $106^{\circ}$ & $15 \%$ & \\
\hline
\end{tabular}

Knee stability was assessed by problems squatting and the knees giving way. Instability of the knee is caused by an imbalance due to tear/rupture of the stabilising structures
[23]. Consistent with existing literature, large number $(70 \%)$ of patients noted problems squatting [24]. More than half the patients found no change to their daily activity. In this study, $16 \%$ of knees never gave way, $63 \%$ sometimes gave way, and $21 \%$ regularly gave way. Similar results were reported by Shapiro et al. who reported that $43 \%$ of their patients had knees giving way occasionally [19]. Patients often complained of knees giving way during inclined exertion such as going up and down stairs and ramps. This is consistent with the findings of Harner et al. who used the Lyshlom score [17]. The majority of the patients in this study did not report instability unless attempting strenuous activities requiring aggressive changes in direction pivoting [17]. The incidence of instability is higher in patients with uni-cruciate repair. Uni-curciate repair however, has lower incidence of stiffness [18]. Studies that trialed repair of both circulate ligaments noted that none of the patients suffered from instability $[25,26]$. Consistent with recent literature, all patients in this study underwent repair of one of the ligamentus stabalising structures [15]. Overall, most patients had negligible or minimal limitation to their activities of daily living, with instability not being a great concern.

Pain and swelling was noted immediately post operatively in all patients who underwent surgical repair. These are the most common side effect of all surgeries. The most important factors contributing to pain are instability, condral injury and posttraumatic arthritis [18]. Uni-cruciate repairs have been found to have higher instability, pain and subsequently arthritis compared to bi-cruciate repairs [19]. Patients who underwent late treatment were found more likely to have pain compared to patients who underwent early treatment [27]. Late treatment is defined as greater than two week after injury. The pattern of injury also determines the level of pain. Patients with associated fractures and meniscus injury suffered more pain in the short and long term [28]. The level of pain varied significantly between studies. After rehabilitation, Montgomery et al. reported pain in $8 \%$ of his patients [34] whereas Noyes and Barber-Westin reported that pain was present in all his patients [27]. In most cases, pain is controlled effectively with analgesia but poorly controlled pain can be disabling and affect the patient's 
rehabilitation and ultimately quality of life. After surgery, all patients in this series complained of pain. The average pain score was 7. After repair, patient's level of pain was severe enough to limit their return to activities of daily living. 3 months after surgery, the average level of pain was 4 . Patients tolerated slight pain and instability and it did not seem to preclude their return to work or sport [2]. At the time of the questionnaire, average pain score was 2. Long term pain after knee surgery is attributed to post traumatic arthritis and psychological factors. After treatment and rehabilitation, 4 patients were completely pain free. 16 $(80 \%)$ of patients had an acceptable level of pain. One patient had recurrently high pain that was treated with arthrodesis after which his pain score was 'acceptable'. Lower pain rates can be achieved by counselling patients regarding realistic expectations of their recovered knee and post operative pain [18].

Return to work post surgical repair is dependent on the type of employment. Physical disability has great impact on patients who work as labourers. Return to work was assessed in outpatient clinic and again using the questionnaire. Given that a functional deficit exists in all repaired knees, it can be assumed that patients cannot return to work and sport in the same capacity as prior to the injury. Minimal literature exists regarding post surgical level of work. The number of patients returning to work varied greatly depending on the study. On the higher end, Yeh et al. reported $91 \%$ patients returning to work [29]. On the lower end, Walker et al. reported only $11 \%$ of patients returning to work [30]. The data from the questionnaire revealed that most patients were able to return to unmodified work. Some patients had severe limitation in their ability to work. Return to work is affected by the level of activity the job entails. As expected, patients undertaking heavy activity (manual labor) were able to return to $71 \%$ of their pre injury work capacity while patients with more sedentary jobs were able to return to $86 \%$ of their pre injury work capacity. Patients who performed sedentary/desk work usually returned to work within two weeks, but those who performed strenuous manual work did not return to work until six to nine months [2].

Return to sport after surgical repair is assessed in OPD and the questionnaire. Patients were discouraged to return to sport for at least 12 months since knee repair. Surgical repair however leaves the knee with a residual disability and this would have a detrimental effect on level of activity. This effect differs based on the level of activity. Due to the loss of the functional reserve, loss of sporting ability would vary based on the pre-injury level of activity. The rate of return to unrestricted sports varied significantly between $8 \%$ [25] $1 \%$ [26]. Limited data exists on return to sporting activity relative to pre-injury status. Wong et al. found that none of his patients were able to return to their level of sporting activities prior to their injuries [24]. All patients were studied together and no comment was made regarding the status of their athletic ability prior to injury (eg heavy/competitive athletes). Patients who were mostly sedentary, engaging in recreational sport prior to injury would find it easier to return to their previous level compared to patients who are in competitive level sports. It is possible for patients can return to their previous sporting class but not in the same capacity. An evidence gap exists regarding the capacity of patients to return to sports and activity. In the questionnaire, patient's pre-injury, immediately post-treatment, 3 months post-injury and current level of activity were assessed. Activity is divided into competitive, heavy, moderate and low. Questions also assessed their percentage return to sport and athletic activity. None of the patients achieved a higher level of activity than before the injury. Seven (35\%) of patients achieved the same level of activity as before injury. Out of the patients who had a competitive and high level of preinjury activity, only 5 of the 17 patients returned to their previous level of activity. Competitive athletes who returned to the same level of activity as before the injury felt they returned to $80 \%$ of their sporting level prior to their injury. Even though several patients returned to the same category of sporting activity, none of them were able to perform at the same level as prior to injury. Five patients were unable to return to any level of sport. This loss in function preventing patients from returning to their previous level of sports and activity was attributed to residual scarring from the injury $[18,24]$.

Patient satisfaction is a commonly used concept that cannot be measured or validated against specific criteria. Satisfaction is affected by many factors unrelated to the surgical intervention. Regardless of this, satisfaction of treatment is of general interest to the surgeons and the hospital [31]. Several studies have attempted to identify factors contributing to patient satisfaction. These studies were limited to patients treated with arthoplasty secondary to arthritis or uni-cruciate reconstruction secondary to sports injuries. Demographics such as age, gender and chronicity of injury did not have any significant relationship to patient satisfaction. In this study, most patients were satisfied with their outcome. All dissatisfied patients suffered postoperative complications. The four dissatisfied patients suffered from wound infections, compartment syndrome and pulmonary embolism. This was consistent with literature that found that the presence of pain, instability, effusion, tenderness of the joint line, loss of extension and post operative complications were significantly associated with patient satisfaction [32]. Sernert also found patient expectations to correlate strongest with satisfaction [33]. Given the traumatic nature of knee dislocations, it is important to define reasonable patient expectations that can be attained through treatment and rehabilitation. Patients treated at the RAH were counselled on the seriousness of their injury and the likely outcomes. All patients felt that their lifestyle had been adversely affected compared with their pre-injury state. Despite this, $80 \%$ of the patients were satisfied out of whom half were very satisfied with their outcome.

\section{CONCLUSION}

Knee dislocation is a serious injury with significant morbidity despite marked improvements in treatment. Most patients were able to achieve a 'satisfactory' range of motion at their knee joint for activities of daily living. Patients were able to return to work and engage in sporting activities but many experienced problems returning to pre-injury level of activity, stability, squatting and running. Despite the high morbidity of the injury, patients were often aware of the seriousness of their injury and were satisfied with the endresult. Post operatively complications had a greater impact on satisfaction than the functional outcome of the repair. Proper counselling and establishing expectation are important in maximising the level of satisfaction. 


\section{APPENDIX 1}

NAME:

Date of knee injury:

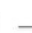

Side: left / right

Todays date:

\section{LEVEL OF ACTIVTY}

Please indicate in the spaces below the HIGHEST level of activity that you participated in BEFORE YOUR KNEE INJURY and the highest level you were able to participate in AFTER the injury and CURRENTLY. (Please refer to scale below)

BEFORE INJURY: Level

AFTER INJURY: Leve

(after treatment and discharge from hospital)

AFTER INJURY: Level

( 3 months after treatment and discharge from hospital)

CURRENTLY: Level

\begin{tabular}{|c|c|}
\hline Level 10 & Competitive sports- soccer, football, rugby (national elite) \\
\hline Level 9 & $\begin{array}{l}\text { Competitive sports- soccer, football, rugby (lower divisions), ice hockey, } \\
\text { wrestling, gymnastics, basketball }\end{array}$ \\
\hline Level 8 & $\begin{array}{l}\text { Competitive sports- racquetball or bandy, squash or badminton, track and field } \\
\text { athletics (jumping, etc.), down-hill skiing }\end{array}$ \\
\hline Level 7 & $\begin{array}{l}\text { Competitive sports- tennis, running, motorcars speedway, handball } \\
\text { Recreational sports- soccer, football, rugby, bandy, ice hockey, basketball, } \\
\text { squash, racquetball, running }\end{array}$ \\
\hline Level 6 & $\begin{array}{l}\text { Recreational sports- tennis and badminton, handball, racquetball, down-hill } \\
\text { skiing, jogging at least } 5 \text { times per week }\end{array}$ \\
\hline Level 5 & $\begin{array}{l}\text { Work- heavy labor (construction, etc.) } \\
\text { Competitive sports- cycling, cross-country skiing, } \\
\text { Recreational sports- jogging on uneven ground at least twice weekly }\end{array}$ \\
\hline Level 4 & Work- moderately heavy labor (e.g. truck driving, etc.) \\
\hline Level 3 & Work- light labor (nursing, etc.) \\
\hline Level 2 & $\begin{array}{l}\text { Work- light labor } \\
\text { Walking on uneven ground possible, but impossible to back pack or hike }\end{array}$ \\
\hline Level 1 & Work- sedentary (secretarial, etc.) \\
\hline Level 0 & Sick leave or disability pension because of knee problems \\
\hline
\end{tabular}

\section{FUNCTION AND KNEE STABILITY}

These questions concern your current knee function and stability. Please tick relevant box. i) Do you feel that your knee might give way?

ii) Do you have difficulty with stairs?

iii) Do you have difficulty with running?

iv) Does your knee lock? How frequently?

v) Do you get swelling in your knee? How frequently?

vi) Do you have difficulty with squatting?

vii) What support do you generally use?

$\square$ none

$\square$ walking stick for long walks

․ walking stick for most of the time

$\square$ one crutch

$\square$ two walking sticks

$\square$ two crutches, frame

not able to walk

viii) How much limp do you have when walking without support?

$\square$ none

$\square$ slight

$\square$ moderate

$\square$ severe

If you have a limp, do you believe it is due to your knee injury? Yes / No

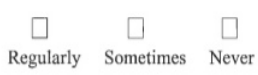

$\square$ Regularly Sometimes Never

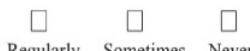

Regularly Sometimes Never
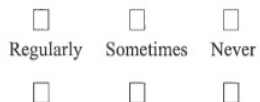

Regularly Sometimes Never

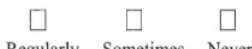

Regularly Sometimes Never

ix) Overall, what percentage return to the following activities were you able to achieve after your injury treatment. ( $0 \%$ no return at all to pre-injury activity, $100 \%$ returned fully to pre-injury activity) Normal activities of daily living

Work

Sport/athletic activity

.........\%

.........\% or NOT APPLICABLE as did not work prior to injury

.........\% or NOT APPLICABLE as no participation in sporting or athletic activity prior to injury

\section{PAIN}

On scale of 1-10, what was your pain

i) IMMEDIATELY AFTER TREATMENT AND DISCHARGE from hospital? (Please circle number)

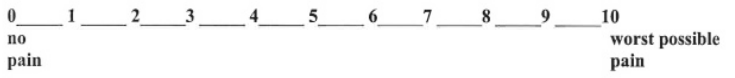

ii) THREE MONTHS AFTER TREATMENT AND DISCHARGE from hospital? (Please circle number)

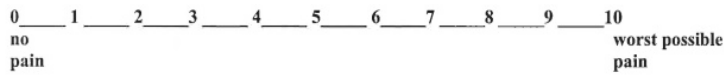

iii) What is your pain CURRENTLY? (Please circle number)

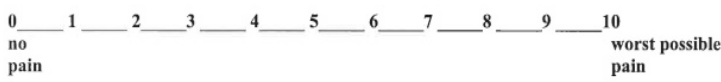

iv) If you CURRENTLY have knee pain, do you believe this pain is due to your original knee injury and treatment or due to other unrelated problems? (Please tick and describe as necessary)

Due to original injury

Due to unrelated problems. Please describe:

\section{SURGICAL HISTORY}

Have you had any additional surgery or non-surgical procedures to your knee other than those

performed at the Royal Adelaide Hospital after your knee injury?

If Yes:

What procedure(s) were performed?

When was the surgery performed?

Who performed the surgery?

\section{COMPLICATIONS}

Have you had any complications associated with your knee treatment that did not require

additional surgery or non-surgical procedures? For example pain, redness, instability? Yes / No

If Yes:

What complication(s) did you have?

Did you consult a health practitioner regarding these problems?

How was the complication treated?

\section{SATISFACTION WITH TREATMENT}

How SATISFIED are you with the results of your treatment for your knee injury?

$\square$ Very satisfied

Somewhat satisfied

Somewhat dissatisfied

$\square$ Very dissatisfied 


\section{REFERENCES}

[1] Meyers MH, Harvey JP Jr. Traumatic dislocation of the knee joint: A study of eighteen cases. J Bone Joint Surg Am 1971; 53(1): 1629.

[2] Harner CD, Waltrip RL, Bennett CH, Francis KA, Cole B, Irrgang JJ. Surgical management of knee dislocations. J Bone Joint Surg Am 2004; 86-A(2): 262-73.

[3] Kaufman SL, Martin LG. Arterial injuries associated with complete dislocation of the knee. Radiology 1992; 184(1): 153-5.

[4] Merrill KD. Knee dislocations with vascular injuries. Orthop Clin North Am 1994; 25(4): 707-13.

[5] Welling RE, Kakkasseril J, Cranley JJ. Complete dislocations of the knee with popliteal vascular injury. J Trauma 1981; 21(6): 4503 .

[6] Swenson TM. Physical diagnosis of the multiple-ligament-injured knee. Clin Sports Med 2000; 19(3): 415-23.

[7] Yahya MM, Mwipatayi BP, Abbas M, Raof S, Sieunarine K. Popliteal artery injury: Royal Perth experience and literature review. ANZ J Surg 2005; 75(10): 882-6.

[8] Abou-Sayed H, Berger DL. Blunt lower extremity trauma and popliteal artery injuries: Revisiting the case for selective arteriography. Arch Surg 2002; 137(5): 585-9.

[9] Fanelli GC, Orcutt DR, Edson CJ. The multiple-ligament injured knee: Evaluation, treatment, and results. Arthroscopy 2005; 21(4): 471-86.

[10] Kennedy JC. Complete dislocation of the knee joint. J Bone Joint Surg Am 1963; 45: 889-904.

[11] Shields L, Mital M, Cave EF. Complete dislocation of the knee: Experience at the Massachusetts General Hospital. J Trauma 1969; 9(3): 192-215.

[12] Liow RY, McNicholas MJ, Keating JF, Nutton RW. Ligament repair and reconstruction in traumatic dislocation of the knee. $\mathrm{J}$ Bone Joint Surg 2003; 85(6): 845-51.

[13] Mitchell JT. Dislocation of the knee. J Bone Joint Surg Am 1930; 12: 640-642.

[14] Shelbourne KD, Porter DA, Clingman JA, et al. Low-velocity knee

[15] dislocation. Orthop Rev 1991; 20(11): 995-1004.

[16] Schenck RC Jr, Hunter RE, Ostrum RF, Perry CR. Knee dislocations. Instr Course Lect 1999; 48: 515-22.

[17] Tegner Y, Lysholm J. Rating systems in the evaluation of knee ligament injuries. Clin Orthop Relat Res 1985; 198: 43-9.

[18] Harner CD, Irrgang JJ, Paul J, Dearwater S, Fu FH. Loss of motion after anterior cruciate ligament reconstruction. Am J Sports Med 1992; 20(5): 499-506.

[19] Almekinders LC, Dedmond BT. Outcomes of the operatively treated knee dislocation. Clin Sports Med 2000; 19(3): 503-18.

[20] Shapiro MS, Freedman EL. Allograft reconstruction of the anterior and posterior cruciate ligaments after traumatic knee dislocation. Am J Sports Med 1995; 23(5): 580-7.
[21] Fanelli GC, Orcutt DR, Edson CJ. The multiple-ligament injured knee: Evaluation, treatment, and results. Arthroscopy 2005; 21(4): 471-86.

[22] Klimkiewicz JJ, Petrie RS, Harner CD. Surgical treatment of combined injury to anterior cruciate ligament, posterior cruciate ligament, and medial structures. Clin Sports Med 2000; 19(3): 47992.

[23] Tzurbakis M, Diamantopoulos A, Xenakis T, Georgoulis A. Surgical treatment of multiple knee ligament injuries in 44 patients: 2-8 years follow-up results. Knee Surg Sports Traumatol Arthrosc 2006; 14(8): 739-49.

[24] Gillquist J, Liljedahl SO, Lindvall H. Reconstruction for old rupture of the anterior cruciate ligament. A follow-up study. Injury 1971; 2(4): 271-8.

[25] Wong CH, Tan JL, Chang HC, Khin LW, Low CO. Knee dislocations - A retrospective study comparing operative versus closed immobilization treatment outcomes. Knee Surg Sports Traumatol Arthrosc 2004; 12(6): 540-4.

[26] Ibrahim SA. Primary repair of the cruciate and collateral ligaments after traumatic dislocation of the knee. J Bone Joint Surg Br 1999; 81(6): 987-90.

[27] Wascher DC, Becker JR, Dexter JG, Blevins FT. Reconstruction of the anterior and posterior cruciate ligaments after knee dislocation. Results using fresh-frozen non-irradiated allografts. Am J Sports Med 1999; 27(2): 189-96.

[28] Noyes FR, Barber-Westin SD. Reconstruction of the anterior and posterior cruciate ligaments after knee dislocation: Use of early postoperative motion to decrease arthrofibrosis. Am J Sports Med 1997; 25(6): 769-78.

[29] Roos EM, Roos HP, Ekdahl C, Lohmander LS. Knee injury and Osteoarthritis Outcome Score (KOOS)-validation of a Swedish version. Scand J Med Sci Sports 1998; 8(6): 439-48.

[30] Yeh WL, Tu YK, Su JY, Hsu RW. Knee dislocation: treatment of high velocity knee dislocation. J Trauma 1999; 46(4): 693-701.

[31] Walker DN, Hardison R, Schenck RC. A baker's dozen of knee dislocations. Am J Knee Surg 1994; 7: 117-124.

[32] Robertsson O, Dunbar M, Pehrsson T, Knutson K, Lidgren L. Patient satisfaction after knee arthroplasty: A report on 27,372 knees operated on between 1981 and 1995 in Sweden. Acta Orthop Scand 2000; 71(3): 262-7.

[33] Kocher MS, Steadman JR, Briggs K, Zurakowski D, Sterett WI, Hawkins RJ. Determinants of patient satisfaction with outcome after anterior cruciate ligament reconstruction. J Bone Joint Surg Am 2002; 84-A(9): 1560-72.

[34] Sernert N, Kartus J, Stener S, Larsson J, Eriksson BI, Karlsson J. Analysis of subjective, objective and functional examination tests after anterior cruciate ligament reconstruction. A follow-up of 527 patients. Knee Surg Sports Traumatol Arthrosc 1999; 7: 160-5.

This is an open access article licensed under the terms of the Creative Commons Attribution Non-Commercial License (http://creativecommons.org/licenses/by-nc/ 3.0/) which permits unrestricted, non-commercial use, distribution and reproduction in any medium, provided the work is properly cited. 